\title{
COMPARATIVE STUDY OF THE RADIOCARBON DATING OF DIFFERENT BONE COLLAGEN PREPARATIONS
}

\author{
D M GURFINKEL \\ Collegium Archaeometricum, c/o Department of Metallurgy \\ and Materials Science, University of Toronto \\ Toronto, Ontario, Canada M5S 1 A4
}

\begin{abstract}
Four different bone collagen preparation procedures were compared and were found useful as a means of assessing the nature of contaminants present in a sample. Weathered bone however appeared to contain contaminants that could not be eliminated by any of the procedures studied.
\end{abstract}

\section{INTRODUCTION}

In this study the bone samples described were dated by accelerator mass spectrometry (AMS) at the Isotrace Laboratory of the University of Toronto. Four different bone collagen preparation procedures were compared, with the intention of determining the nature of contaminants present and assessing the most reliable age. A comparison was also made between the dating of spongy and compact bone and weathered and unweathered bone.

\section{SAMPLES}

Three bone samples were used:

TO-34: This was a bison metacarpal obtained from the Northern Yukon Research Project of the University of Toronto and found at Old Crow River (locality 11) Yukon Territory. It was from a group of bones several of which had been previously dated by conventional radiocarbon methods although the bison bone obtained here had not been directly dated.

TO-30: This was a portion of a whale bone obtained from the Geological Survey of Canada (GSC) which was found at Cape Storm on Ellesmere Island, North West Territory and had been previously dated.

TO-33: This was a portion of a whale rib obtained from GSC which was found near Rosse Bay, Ellesmere Island and which had been previously dated. It had been found only partly buried and the exposed portion showed considerable signs of weathering. Because of the small sample size requirement of AMS and the relatively large amount of rib available it was possible to subdivide this sample into three sections:

1) compact bone-good quality (ie, the buried portion of bone)

2) compact bone-weathered (ie, the exposed portion of bone)

3) spongy bone (removed from interior portion of bone, $\sim 10 \mathrm{~cm}$ from one end).

This subdivision provided an opportunity to compare both weathered and spongy bone, considered poor dating material, to the better quality compact bone, with the bone sample effectively acting as its own control.

A summary of the results of previously obtained ages for these samples is shown in Table 1. 
TABLE 1

Sample ages obtained by conventional methods

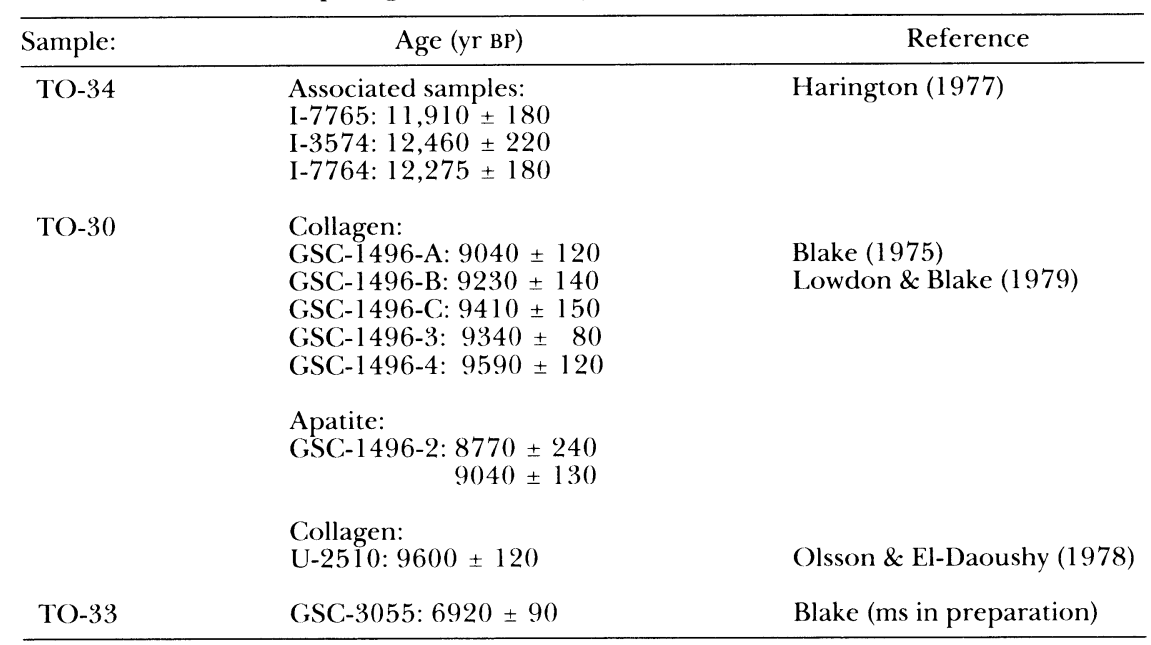

\section{METHODS OF COLLAGEN PREPARATION}

The basic principle behind any pretreatment is to recover from the sample a fraction that originates from the sample itself, free of carbon-containing environmental contaminants. For bone, collagen is generally considered the preferred dating fraction. Early pretreatment procedures involved the recovery of collagen as the insoluble residue remaining after acid extraction (Tamers \& Pearson, 1965; Berger, Horney \& Libby, 1964; Sellstedt, Engstrand \& Gejvall, 1966). Acid treatment dissolved the bone apatite and decomposed secondary carbonates which constituted a major source of carbon contamination.

Humic substances were also recognized as a major source of contamination and as they are largely alkali-soluble (Stevenson, 1982, p 43) $\mathrm{NaOH}$ extraction was incorporated as a means of eliminating them from bone (Haynes, 1967).

Longin (1971) introduced an additional method for collagen purification which was the conversion of the collagen recovered as an acid-insoluble residue to a soluble gelatin by dissolution in hot water. This was intended to remove hot water-insoluble contaminants such as many humic substances and carbon particulates.

Berglund, Håkansson and Lagerlund (1976) incorporated this step after both acid and alkali treatment.

Three major steps then, acid extraction, alkali extraction, and gelatin conversion separately or in combination, constitute the general approach taken to the pretreatment of bone. Other pretreatments, of course, have been developed such as EDTA extraction (Olsson et al, 1974) and particularly since the advent of AMS, the isolation of total amino acids and/or specific amino acid fractions (eg, Taylor \& Slota, 1979; Donahue, Jull \& Zabel, 1984; Gillespie, Hedges \& Wand, 1984). 
In order to determine the nature of contaminants present in bone, the major pretreatment steps were incorporated into the scheme shown in Figure 1. If secondary carbonates were the major contaminants present, then no difference would be observed between the four collagen preparations as the $\mathrm{HCl}$ extraction was common to all. If humic substances were a major and presumably younger-aged contaminant, then methods B, C and D would be expected to yield older ages than method $\mathrm{A}$. If a large proportion of contamination was from highly insoluble and younger-aged material, then methods B and D would yield the oldest ages.

Bone samples were prepared by each of the four methods outlined in Figure 1. Only $100 \mathrm{mg}$ of starting material were required as the samples, being from Arctic locations, were very well-preserved. Collagen yields are shown in Table 2. A portion of each collagen residue, containing the equivalent of 4 to $6 \mathrm{mg}$ carbon, was combusted and acetylene gas synthesized from the resultant carbon dioxide. From each batch of acetylene gas up to four solid carbon targets were prepared by a "cracking" process. The results shown in Figures 2, 3 and 4 are the age determinations obtained from two or three such replicate targets. The combustion, acetylene synthesis and cracking procedures are detailed by Beukens, Gurfinkel, and Lee (1986) and Gurfinkel (ms in preparation).

\section{DISCUSSION OF RESULTS}

Results obtained for bison bone TO-34 illustrate how the comparison of the four procedures can be used to determine the nature of contami-

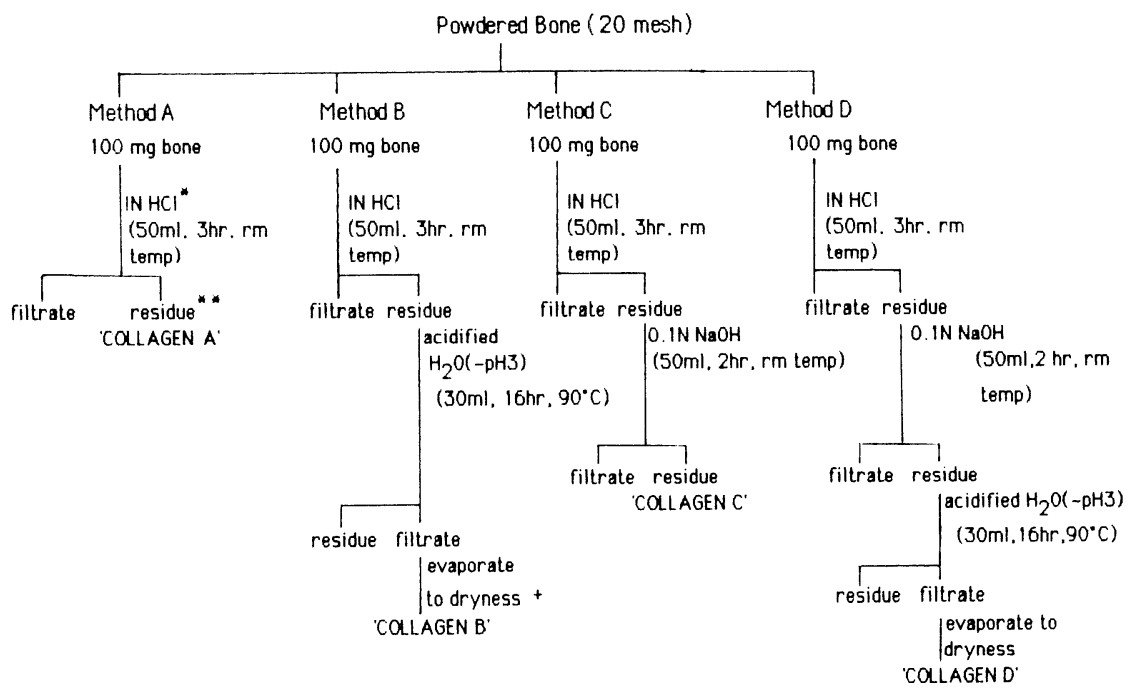

* All extractions were performed in glass beakers, with stirring.

** All residues were washed with water to neutralization. Base extract residues were also washed with $1 \mathrm{~N} \mathrm{HCl}$ to eliminate any contamination due to atmospheric carbon dioxide.

+ Filtrate was evaporated under reduced pressure and with gentle heating to a volume of ca $1 \mathrm{ml}$. This $1 \mathrm{ml}$ volume was transferred to a small test tube and evaporated to dryness under a stream of argon. The test tube was then introduced into the combustion system as described elsewhere (see text).

Fig 1. Collagen preparation methods 
TABLE 2

Bone collagen yield

\begin{tabular}{lrrrr}
\hline Sample & \multicolumn{4}{c}{ \% collagen yield* } \\
\hline & \multicolumn{4}{c}{ Preparation method } \\
TO-34 & A & B & C & D \\
TO-30 & $10 \pm 1 * *$ & $9 \pm 1$ & $8 \pm 1$ & $9 \pm 1$ \\
TO-33: & $12 \pm 1$ & $11 \pm 1$ & $12 \pm 1$ & $11 \pm 1$ \\
Section 1: good quality compact bone & $15 \pm 1$ & $8 \pm 1$ & $14 \pm 1$ & $12 \pm 1$ \\
Section 2: weathered compact bone & $13 \pm 1$ & $7 \pm 1$ & $14 \pm 1$ & $16 \pm 1$ \\
Section 3: spongy bone & $13 \pm 1$ & $12 \pm 1$ & $18 \pm 1$ & $11 \pm 1$
\end{tabular}

* \% collagen yields were initially calculated as (wt of collagen residue/initial wt of bone) $\times 100$. However, considerable variability was observed in yields determined this way, attributed to incomplete drying of the collagen residues. For this reason $\%$ collagen yields were recalculated based on the amount of carbon dioxide recovered converted to the weight of collagen residue by assuming collagen had a $50 \%$ carbon content. These are shown above. The $50 \%$ carbon figure was determined by repeated combustion of purified collagen (bovine tendon, obtained from Sigma Chemical $\mathrm{Co}$ ) and was consistent with $\% \mathrm{C}$ as calculated from the known amino acid content of collagen.

** This crror estimation was determined by first calculating a single combined error from the errors of each of the directly measured quantities used to calculate yield. This combined error was then doubled as this was considered a reasonable estimate of the additional error in the collagen yield due to small but variable sample losses which occurred during the handling of the residues through the various extraction steps.

nants present. It is evident from Figure 2 that younger-aged contaminants were not removed by $\mathrm{HCl}$ extraction alone (Method $\mathrm{A}$ ) and while the additional gelatin conversion step (Method B) was more effective, alkali extraction was most effective in eliminating the contaminants (Methods $\mathrm{C}$ and D). In light of this alkali solubility, these contaminants were most likely humic substances. Because of this, the most reliable age was judged to be the average of Methods $\mathrm{C}$ and $\mathrm{D}: 12,610 \pm 70 \mathrm{yr} \mathrm{BP}$, and this was in good agreement with previously obtained dates (Table 1).

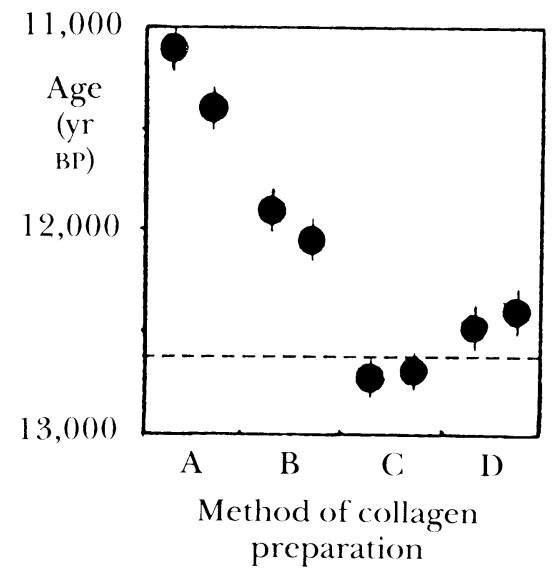

Fig 2. Results for TO-34: bison metacarpal; dotted line indicates average age for Methods $\mathrm{C}$ and $\mathrm{D}$. 


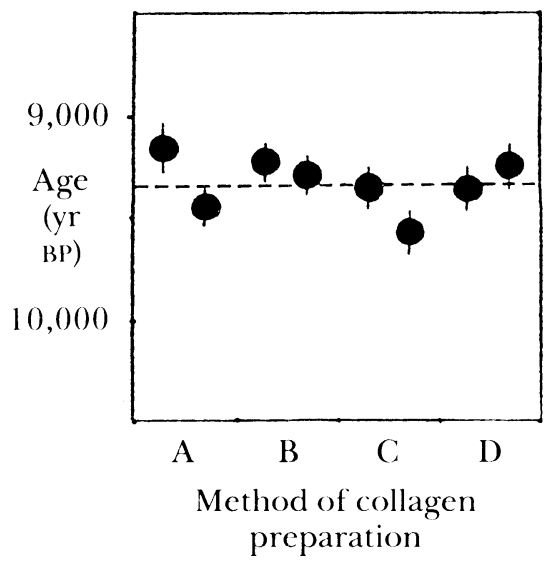

Fig 3. Results for TO-30: whale bone; dotted line indicates overall average age.

Although variation in age with chemical treatment was evident, there was little variation in the collagen recovery between the different preparation methods for TO-34 (see Table 2). This was not surprising as only $4 \%$ contamination of the collagen residue with modern material having a similar C-content to collagen (or ca $8 \%$ contamination with 5000-yr-old material) would be necessary to produce the shift from the maximum to minimum age observed for this sample. Such a level of contamination could not be accurately detected given the error associated with collagen yields in this study (see footnote, Table 2).

The ages obtained for TO-30 (Fig 3 ) as well as the similarity in collagen yields (Table 2) indicate that, for this sample, there was no difference between the preparation procedures. In this case then, the best age esti-

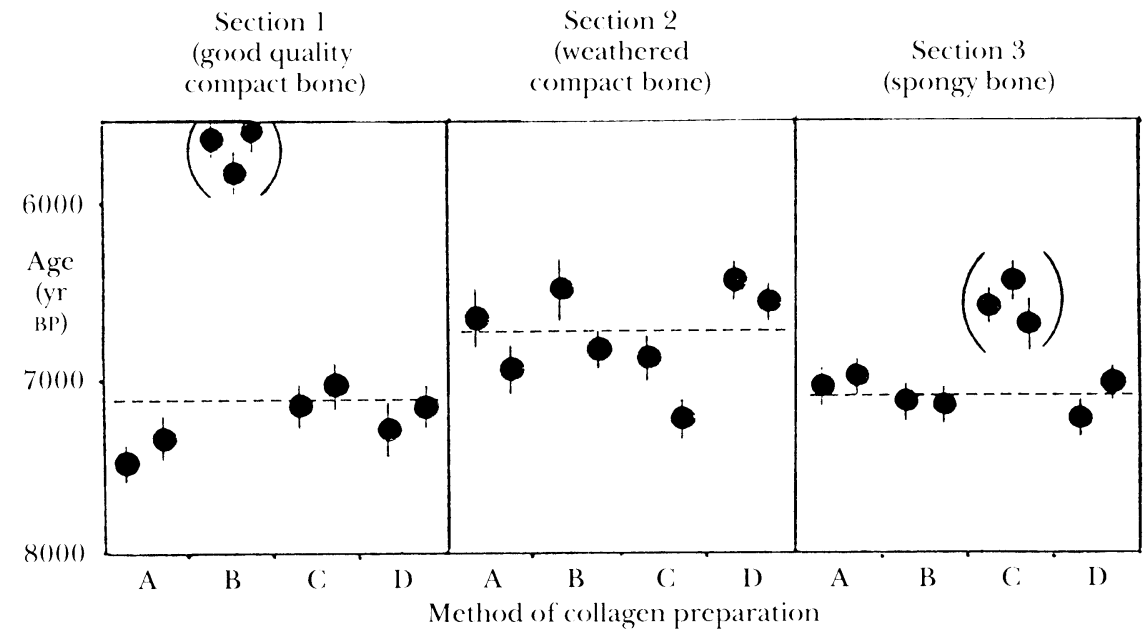

Fig 4. Results for TO-33: whale rib; dotted line indicates average age for each section, bracketed points excluded. See text for explanation. 
mate was considered to be average of the four preparations, $9350 \pm 40 \mathrm{yr}$ $\mathrm{BP}$, which was consistent with other age determinations for this sample (Table 1).

There were three possible reasons for the concordance between the four methods:

1) no major contaminants were present or at least none of an age different from that of the bone. This appeared unlikely as previously obtained apatite dates (see Table 1) were somewhat younger than the collagen dates, suggesting that a younger-aged contaminant was indeed present;

2) the major contaminant present, eg, secondary carbonate, was removed by the $\mathrm{HCl}$ extraction which was common to all procedures. This was a likely explanation as the younger-aged contaminant noted above might well have been secondary carbonate;

3) contaminants were present that were not eliminated by any of the procedures used. Unfortunately, the plausibility of this explanation could not be determined from the existing data.

The ages obtained for TO-33 (Fig 4), however, did provide an example of the third explanation above, $i e$, incomplete contaminant removal by all four methods. For this sample three sections were dated and no major differences in age between collagen preparation methods were apparent within each section except Method B in Section 1, which produced an anomalously young date. This result was believed due to an irregular acetylene synthesis process likely caused by a vacuum line leak. The second exception was Section 3, Method C, and an explanation for this follows.

The ages obtained for the good quality compact bone, Section 1, which, excluding Method B, averaged $7120 \pm 25$ yr BP, were in good agreement with the previously obtained age (Table 1) and were assumed to represent the best estimate of the true age of the bone. Compared to these, the weathered bone (Section 2 ) showed a clear trend toward younger ages, the overall average being $6740 \pm 100 \mathrm{yr}$ BP. Both the weathered and good-quality compact bone had similar collagen yields (Table 2). This suggested that the shift in average ages observed was the result of a weathering process which introduced contaminants into the bone but did not cause extensive collagen degradation. Only $2 \%$ contamination with modern material (or ca $4 \%$ contamination with 5000 -yr-old material) would produce the age shift observed here and, as previously noted, with sample TO-34 this was too low a level to be detected from collagen yields. For both bone sections, Method $\mathrm{B}$ produced unusually low collagen yields. The reason for this was not clear and may merely represent excessive and coincidental sample losses during preparation. While Method B in Section 1 had an anomalously young age, this anomaly was more likely due to the explanation given above than related to collagen yield.

With respect to the spongy bone, all methods except $\mathrm{C}$ produced dates consistent with Section 1. While the sections were finely ground to ensure homogeneity, the possibility that the same contaminants present in the weathered bone may have been present in the particular sample aliquot prepared by Method $\mathrm{C}$ and were responsible for its younger age cannot be ruled out. The fact that the collagen yield (Table 2 ) for Method $\mathrm{C}$ was some- 
what higher than the other three fractions for this section also suggested possible sample heterogeneity.

\section{CONCLUSIONS}

From the above results the following conclusions can be drawn:

1) the scheme shown in Figure 1 is useful in determining the nature of contaminants present in a sample;

2) the results of TO-34 suggest that alkali-extraction is more effective than Longin's gelatin conversion in removing humic acid contaminants;

3) weathering processes appear to introduce contaminants that are not completely removed by the procedures described here. It should be recognized that the bones used in these experiments were from the Arctic and showed very good collagen preservation. One can only assume that in poorly preserved bone, where contaminants might represent a much higher proportion of total carbon, this problem would be aggravated. Further investigation in this area is clearly required.

\section{ACKNOWLEDGMENTS}

The author wishes to acknowledge the financial support of this work by the University of Toronto, the Natural Sciences and Engineering Research Council, Energy, Mines, and Resources of Canada, and Environment Canada.

I would like to thank W Blake, Jr, Geological Survey of Canada, and W Irving, University of Toronto, for donating the samples used in this study. Thanks go also to H Polach, Australian National University, for the discussions of the summer of 1983 .

I wish to extend my appreciation to the able staff of the Isotrace Laboratory, especially $\mathrm{R}$ Beukens, $\mathrm{C}$ Bowen, $\mathrm{H}$ Lee, and $\mathrm{L}$ Vasserman with whom I worked closely on the radiocarbon dating project and to $\mathrm{A} \mathrm{E}$ Litherland, Isotrace Director, for encouragement and guidance.

Special thanks go to the members of the Collegium Archaeometricum, especially to U M Franklin, whose constant advice, support, and inspiration have been invaluable.

\section{REFERENCES}

Berger, R, Horney, A G and Libby, W F, 1964, Radiocarbon dating of bone and shells from their organic components: Science, v 144, p 999-1001.

Berglund, B E, Håkansson, S and Lagerlund, E, 1976, Radiocarbon-dated mammoth (Mammuthus primigenius Blumenbach) find in South Sweden: Boreas, v 5, p 177-191.

Beukens, R P, Gurfinkel, D M and Lee, H W, 1986, Progress at the Isotrace radiocarbon facility, in Stuiver, M and Kra, R S, eds, Internatl ${ }^{14} \mathrm{C}$ conf, 12th, Proc: Radiocarbon, v 28, no. 2, p 229-236.

Blake, W, Jr, 1975, Radiocarbon age determinations and post-glacial emergence at Cape Storm, Southern Fllesmere Island, Arctic Canada: Geog Annaler, v 57, ser A, p 1-71.

Donahue, R, Jull, A J T and Zabel, T H, 1984, Results of radioisotope measurements at the NSF-University of Arizona tandem accelerator mass spectrometer facility: Nuclear Instruments \& Methods Phys Research Sec B, p 162-166.

Gillespie, R, Hedges, R E M and Wand, J, 1984, Radiocarbon dating of bone by accelerator mass spectrometry: Jour Archeol Sci, v 11, p 165-170.

Harington, C R, (ms) 1977, Pleistocene mammals of the Yukon territory: Ph D dissert, Univ Alberta.

Haynes, C V, 1967, Bone organic matter and radiocarbon dating, in Radiocarbon dating and methods of low-level counting: Vienna, Internatl Atomic Energy Agency, p 163-168. 
Longin, R, 1971, New method of collagen extraction for radiocarbon dating: Nature, $v 230$, no. 5291, p 241-242.

Lowdon, J A and Blake, W, Jr, 1979, Geological Survey of Canada radiocarbon dates XIX: Geol Survey Canada, Paper 79-7.

Olsson, I U and El-Daoushy, M F A F, 1978, Uppsala natural radiocarbon measurements XII: Radiocarbon, v 20, p 469-486.

Olsson, I U, El-Daoushy, M, Farid, A F, Abd-El-Mageed, A I and Klasson, M, 1974, A comparison of different methods for pretreatment of bones I: Geol Foren Stockholm Forh, v 96 p 171-181.

Sellstedt, H, Engstrand, L and Gejvall, N G, 1966, New application of radiocarbon dating to collagen residue in bones: Nature, $v 212, \mathrm{p} 572-574$.

Stevenson, F J, 1982, Humus chemistry: Genesis, composition, reactions: New York, Wiley \& Sons.

Tamers, M A, and Pearson F J, 1965, Validity of radiocarbon dates on bone: Nature, v 208, p $1053-1055$.

Taylor, R E and Slota, P, 1979, Fraction studies on marine shell and bone samples for radiocarbon analyses, in Berger, $\mathrm{R}$ and Suess, $\mathrm{H}$ E, eds, Radiocarbon dating, Internatl ${ }^{14} \mathrm{C}$ conf, 9th, Proc: Berkeley/Los Angeles, Univ California Press, p 422-432. 